University of Nebraska - Lincoln

DigitalCommons@University of Nebraska - Lincoln

USDA National Wildlife Research Center - Staff Publications
U.S. Department of Agriculture: Animal and Plant Health Inspection Service

2009

\title{
Landscape Genetics of Raccoons (Procyon lotor) Associated with Ridges and Valleys of Pennsylvania: Implications for Oral Rabies Vaccination Programs
}

J. Jeffrey Root

USDA/APHIS/WS National Wildlife Research Center, jeff.root@aphis.usda.gov

Robert B. Puskas

United States Department of Agriculture, Wildlife Services, Bolivar, Pennsylvania

Justin W. Fischer

USDA/APHIS/WS National Wildlife Research Center, Justin.w.fischer@aphis.usda.gov

Craig B. Swope

United States Department of Agriculture, Wildlife Services, Bolivar, Pennsylvania

Melissa A. Neubaum

United States Department of Agriculture, Wildlife Services, National Wildlife Research Center, Fort Collins, Colorado

See next page for additional authors

Follow this and additional works at: https://digitalcommons.unl.edu/icwdm_usdanwrc

Part of the Environmental Sciences Commons

Root, J. Jeffrey; Puskas, Robert B.; Fischer, Justin W.; Swope, Craig B.; Neubaum, Melissa A.; Reeder, Serena A.; and Piaggio, Antoinette J., "Landscape Genetics of Raccoons (Procyon lotor) Associated with Ridges and Valleys of Pennsylvania: Implications for Oral Rabies Vaccination Programs" (2009). USDA National Wildlife Research Center - Staff Publications. 946.

https://digitalcommons.unl.edu/icwdm_usdanwrc/946

This Article is brought to you for free and open access by the U.S. Department of Agriculture: Animal and Plant Health Inspection Service at DigitalCommons@University of Nebraska - Lincoln. It has been accepted for inclusion in USDA National Wildlife Research Center - Staff Publications by an authorized administrator of DigitalCommons@University of Nebraska - Lincoln. 


\section{Authors}

J. Jeffrey Root, Robert B. Puskas, Justin W. Fischer, Craig B. Swope, Melissa A. Neubaum, Serena A. Reeder, and Antoinette J. Piaggio 


\title{
Landscape Genetics of Raccoons (Procyon lotor) Associated with Ridges and Valleys of Pennsylvania: Implications for Oral Rabies Vaccination Programs
}

\author{
J. Jeffrey Root, ${ }^{1}$ Robert B. Puskas, ${ }^{2}$ Justin W. Fischer, ${ }^{1}$ Craig B. Swope, ${ }^{2}$ \\ Melissa A. Neubaum, ${ }^{1}$ Serena A. Reeder, ${ }^{3}$ and Antoinette J. Piaggio ${ }^{1}$
}

\begin{abstract}
Raccoons are the reservoir for the raccoon rabies virus variant in the United States. To combat this threat, oral rabies vaccination (ORV) programs are conducted in many eastern states. To aid in these efforts, the genetic structure of raccoons (Procyon lotor) was assessed in southwestern Pennsylvania to determine if select geographic features (i.e., ridges and valleys) serve as corridors or hindrances to raccoon gene flow (e.g., movement) and, therefore, rabies virus trafficking in this physiographic region. Raccoon DNA samples $(n=185)$ were collected from one ridge site and two adjacent valleys in southwestern Pennsylvania (Westmoreland, Cambria, Fayette, and Somerset counties). Raccoon genetic structure within and among these study sites was characterized at nine microsatellite loci. Results indicated that there was little population subdivision among any sites sampled. Furthermore, analyses using a model-based clustering approach indicated one essentially panmictic population was present among all the raccoons sampled over a reasonably broad geographic area (e.g., sites up to $36 \mathrm{~km}$ apart). However, a signature of isolation by distance was detected, suggesting that widths of ORV zones are critical for success. Combined, these data indicate that geographic features within this landscape influence raccoon gene flow only to a limited extent, suggesting that ridges of this physiographic system will not provide substantial long-term natural barriers to rabies virus trafficking. These results may be of value for future ORV efforts in Pennsylvania and other eastern states with similar landscapes.
\end{abstract}

Key Words: Genetics—Landscape-Pennsylvania-Procyon lotor-Rabies-Raccoon.

\section{Introduction}

$\mathbf{T}$ HE RACCOON (Procyon lotor), a medium-sized mesopredator, is a common inhabitant across most of the United States (Fitzgerald and Meaney 1994), ranging from southern Canada to Panama in the New World (Lotze and Anderson 1979). Raccoons occupy a wide variety of habitat types (Fitzgerald and Meaney 1994) and are well-adapted to anthropogenic conditions (Schmidly 2004).

Until the early 1970s, raccoon rabies, caused by the raccoon rabies virus variant, was reported predominantly in the southeastern states of Florida and Georgia (McLean 1975). However, in the 1970s rabies-infected raccoons were transported from Florida to the Virginia/West Virginia border area where a new focus and epizootic of the raccoon variant of rabies virus was initiated (see Winkler and Jenkins 1991 and citations therein), which evolved into one of the most significant and widespread epizootics in the history of wildlife rabies (Childs et al. 2000). Ultimately, this rabies virus focus expanded throughout the eastern United States (Winkler and Jenkins 1991), north to the Canadian border, east to the Atlantic Ocean, south to the original states of Georgia and Florida, and as far west as Ohio, presenting a significant public health threat over a large geographical region (see USDA 2004).

To combat the threat of terrestrial rabies, the United States Department of Agriculture, Wildlife Services conducts annual cooperative oral rabies vaccination (ORV) programs in several regions of the United States each year for several target wildlife species (e.g., raccoons, coyotes [Canis latrans], and gray fox [Urocyon cineroargenteus]). The raccoon ORV program is concentrated in the eastern United States and uses a

${ }^{1}$ United States Department of Agriculture, Wildlife Services, National Wildlife Research Center, Fort Collins, Colorado.

${ }^{2}$ United States Department of Agriculture, Wildlife Services, Bolivar, Pennsylvania.

${ }^{3}$ U.S. Centers for Disease Control and Prevention, Atlanta, Georgia. 
vaccinia-rabies glycoprotein recombinant virus vaccine (Raboral V-RG ${ }^{\circledR}$ [V-RG], Merial, Athens, GA). The vaccine is placed in sachets in fish meal polymer baits and/or baitcoated sachets to deliver vaccines to raccoons (USDA 2004).

Public health officials reported the first cases of raccoon variant rabies in south-central Pennsylvania in 1982, along the western edge of the ridge-and-valley physiographic region (Moore 1999). The ridge-and-valley system of Pennsylvania was suggested to be a route of dissemination of raccoon rabies soon after the introduction, with extension patterns following the corridors of this system (Moore 1999). Currently, nearly all terrestrial cases of rabies in Pennsylvania are attributed to raccoons (USDA 2006).

Population genetics has recently been used successfully to assess various associations involving the transmission and/or trafficking of select etiologic agents causing wildlife and human (i.e., zoonotic) diseases (e.g., Root et al. 2003, 2004, Blanchong et al. 2007). In addition, these techniques have proven useful for addressing various population aspects of multifaceted invasive species issues (Hampton et al. 2004). Thus, modern genetic techniques, combined with ecologic and etiologic information, have helped researchers to address applied questions of great scope and complexity.

Because a significant number of ORV baits are deployed in the eastern United States each year at a considerable ex- pense, it is important that any key geographic features that enhance or inhibit raccoon gene flow be recognized and described to assess the rabies virus trafficking potential of these animals in various systems. Notably, it has been suggested that the identification of rabies dissemination corridors could be used in prevention or elimination efforts (Moore 1999). Therefore, the objective of this study was to use a landscape genetics approach (Manel et al. 2003) to describe the geographic features, if any, that could hinder or enhance raccoon gene flow and rabies virus trafficking in this mammal. These results may assist future ORV efforts in southwestern Pennsylvania and may have applications to areas with similar habitats and physiographic features.

\section{Materials and Methods}

\section{Study sites and sample collection}

This study was based on and adjacent to Laurel Ridge (hill) in southwestern Pennsylvania (Westmoreland, Cambria, Fayette, and Somerset counties; Fig. 1). This ridge was selected based on elevation, access, and additional logistical considerations (e.g., roads). Although this ridge is located near the edge of the true ridge-and-valley system, its topography has similar geographic features with high elevation hills and deciduous forests. Therefore, Laurel Ridge and ad-

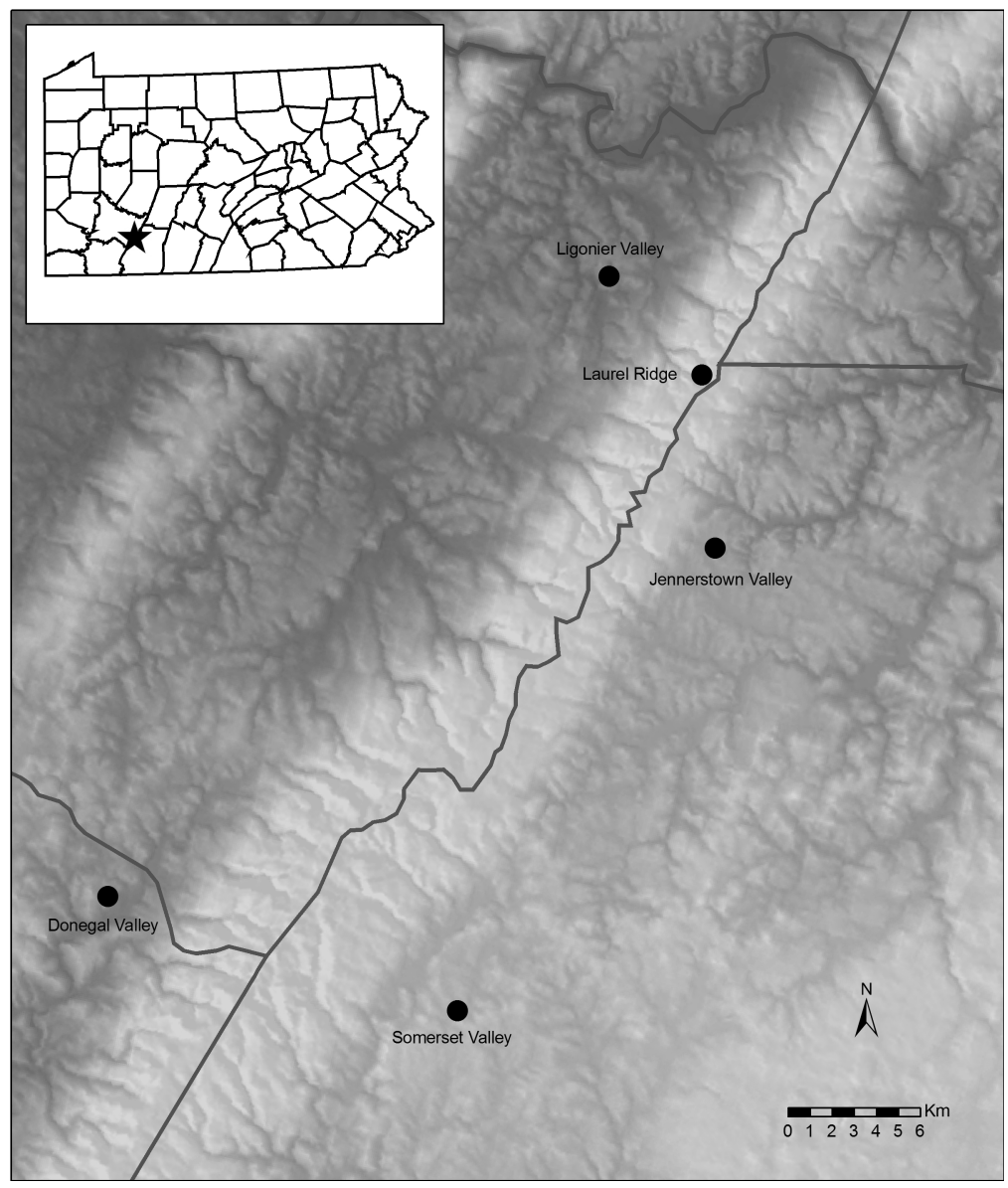

FIG. 1. Centroids of locations of study sites for raccoon DNA collections on and near Laurel Ridge (Hill), southwestern Pennsylvania. Minimum and maximum distances among these sites were $6.1 \mathrm{~km}$ and $36.0 \mathrm{~km}$, respectively. Minimum elevation of collection locations in the valley sites ranged from 335-603 m, and the maximum elevation of collection locations from the ridge site was $874 \mathrm{~m}$. 
jacent valleys (consisting primarily of agricultural and small suburban areas) have excellent geographic features to test various hypotheses associated with raccoon gene flow relevant to ORV programs.

Raccoon tissue samples were strategically collected from five study sites referred to herein as Laurel Ridge (LR), Ligonier Valley (LV), Jennerstown Valley (JV), Donegal Valley (DV), and Somerset Valley (SV; Fig. 1). For clarity, it should be noted that DV, LV, JV, and SV are titled for towns within close proximity of the study sites. However, each pair (i.e., DV-LV and JV-SV) is essentially located within the same valley system (Fig. 1). The minimum and maximum distances between these sites were $6.1 \mathrm{~km}$ and $36.0 \mathrm{~km}$, respectively. As noted above, these study sites encompass heterogeneous habitats, with valley sites having drastically different habitats, resources, and anthropogenic activity than the ridge.

Tissue samples were obtained by live trapping raccoons in appropriate habitats using box traps. Under anesthesia (5:1 mixture of ketamine and xylazine), a small piece of ear tissue was excised from raccoons. In addition, samples were opportunistically collected from road-killed raccoons in the same geographic areas. Following collections, tissue samples were stored in $1 \mathrm{~mL} 70 \%$ ethanol in cryovials at $-20^{\circ} \mathrm{C}$ in field locations and $-80^{\circ} \mathrm{C}$ in the laboratory until DNA extractions were initiated. DNA extractions were conducted from raccoon tissues with DNeasy ${ }^{\circledR}$ Tissue Kits (QIAGEN Inc., Valencia, CA) following the manufacturer's protocol.

\section{DNA amplification and genotyping}

Nine tetranucleotide microsatellite primers developed by Cullingham et al. (2006) were utilized in this study. These included PLO-3C, PLO-M17, PLO-M2, PLO-M20, PLO-M3, PLO2-123, PLO2-14, PLO3-71, and PLO3-86 (Table 1). Polymerase chain reactions essentially followed those outlined by Cullingham et al. (2006). We reamplified 30\% of all samples to confirm genotypes and genotypic reliability. Amplifications were achieved using a BioRad MyCycler thermocycler (Bio-Rad Laboratories, Hercules, CA). Genotypes were visualized using an Applied Biosystems 3130 Genetic Analyzer (Applied Biosystems Inc., Foster City, CA) following the manufacturer's protocols. Alleles were scored by em-

Table 1. Summary Statistics for Raccoon (PRocyon LOTOR) Microsatellite LOCI EMPLOYED IN A LANDSCAPE Genetics Study in Southwestern Pennsylvania

\begin{tabular}{lcrcc}
\hline Locus $^{\mathrm{a}}$ & Size range & & $H_{o}$ & $H_{e}$ \\
\hline PLO-3C & $682-736$ & 20 & 0.840 & 0.890 \\
PLO-M17 & $204-232$ & 7 & 0.720 & 0.729 \\
PLO-M2 & $256-328$ & 14 & 0.872 & 0.868 \\
PLO-M20 & $173-233$ & 15 & 0.839 & 0.841 \\
PLO-M3 & $261-289$ & 8 & 0.779 & 0.782 \\
PLO2-123 & $552-612$ & 14 & 0.890 & 0.873 \\
PLO2-14 & $221-325$ & 27 & 0.914 & 0.898 \\
PLO3-71 & $151-211$ & 15 & 0.840 & 0.858 \\
PLO3-86 & $306-430$ & 26 & $0.780^{\mathrm{b}}$ & 0.908 \\
\hline
\end{tabular}

aLocus, size range of polymerase chain reaction product, number of alleles (A) per locus, mean observed heterozygosity $\left(\mathrm{H}_{\mathrm{o}}\right)$, and mean expected heterozygosity $\left(\mathrm{H}_{\mathrm{e}}\right)$ are listed.

bTwo significant deviations from Hardy-Weinberg equilibrium were noted following Bonferroni corrections.
TABle 2. Summary Statistics For Raccoons

(PRocyon LOTOR) by STUdy Site IN a LANDSCAPE Genetics Study in Southwestern Pennsylvania

\begin{tabular}{lcrcc}
\hline Population $^{\mathrm{a}}$ & $\mathrm{n}$ & A (range) & $H_{o}$ & $H_{e}$ \\
\hline LR & 39 & $12.6(6-17)$ & 0.838 & 0.855 \\
LV & 48 & $12.0(6-16)$ & 0.854 & 0.842 \\
JV & 56 & $13.3(6-20)$ & 0.808 & 0.854 \\
SV & 20 & $9.6(5-14)$ & 0.844 & 0.850 \\
DV & 22 & $10.1(5-14)$ & 0.808 & 0.848 \\
\hline
\end{tabular}

LR, Laurel Ridge; LV, Ligonier Valley; JV, Jennerstown Valley; DV, Donegal Valley; SV, Somerset Valley.

aStudy site, number of individuals per population (n), mean number of alleles (A) and range per locus, mean observed $\left(\mathrm{H}_{\mathrm{O}}\right)$ and expected $\left(\mathrm{H}_{\mathrm{e}}\right)$ heterozygosity are listed.

ploying ABI GeneMapper Software v4.0 and scored data was exported from GeneMapper using GMConvert (Faircloth 2006). Files were formatted to a GENEMAPPER input file and imported into the software package Convert (Glaubitz 2004) for file conversion used in downstream analyses.

\section{Evaluation of population structure}

Hardy-Weinberg equilibrium (HWE), linkage disequilibrium, intracolonial and per locus genetic variability, pairwise $F_{\mathrm{ST}}$ estimates among locations (Weir and Cockerham 1984), linearized $F_{\mathrm{ST}}$ estimates among sampling locations (Slatkin 1995), Mantel tests, and an analysis of molecular variance (AMOVA) were estimated from microsatellite data using Arlequin version 3.1 (Excoffier et al. 2005). For standard $F_{\mathrm{ST}}$ (Weir and Cockerham 1984) estimates, significance was ascertained by generating an expected distribution based on randomizations with Monte Carlo simulations in Arlequin version 3.1 (90,300 permutations; Excoffier et al. 2005). Bonferroni corrections were made to correct for multiple comparisons of these data (Rice 1989) when applicable (e.g., Hardy-Weinberg equilibrium and standard $F_{\mathrm{ST}}$ estimates). In addition, Structure v2.1 (Pritchard et al. 2000) was used to assess the number of genetic clusters $(K)$ within the sampling region, using an admixture model and assuming allele frequencies were correlated $(100,000$ burn in permutations; $1,000,000$ Markov chain permutations). Estimation of $K$ ranged from 1-10 for two to three runs and the best estimate of $\mathrm{K}$ was selected based on the $K$ that had the highest likelihood score and the lowest variance in likelihood estimates. This analysis makes no $a$ priori assumptions of the individual's population (or sampling area) of origin. Genotype geographical associations were also assessed by an assignment test with GeneClass2 (Piry et al. 2004) to infer the population of origin of all raccoons sampled. The Bayesian method described by Rannala and Mountain (1997) was employed using 100,000 simulated individuals (alpha $=0.01$ ).

\section{Results}

Overall, 185 raccoon DNA samples were collected and analyzed. These included 39 from LR, 48 from LV, 56 from JV, 22 from DV, and 20 from SV. The samples were from mixed age and sex classes. The number of alleles per locus ranged from 7.0 to 27.0 (Table 1), while the average number of alleles per population ranged from 9.6 to 13.3 (Table 2). Moder- 
ate linkage disequilibrium was noted in some pairwise comparisons of loci. However, on a per locus basis, linkage disequilibrium was never detected in more than two of five populations. Significant deviations $(p \leq 0.05)$ from HWE were noted in four instances over all loci and populations (e.g., 45 total tests). Following Bonferroni correction (Rice 1989), only two tests remained significant (JV and SV at locus PLO3-86). This locus was not dropped from further analyses because it did not deviate from HWE in most cases.

Using no a priori information about the population of origin of individuals, results from Structure v2.1 indicated that the raccoons sampled at five reasonably distant study sites $(6.1-36.0 \mathrm{~km})$ formed a single genetic population $(K=1)$. The estimation of a single population $(K=1)$ was selected because the log likelihoods estimations were the highest and had the least variability among runs (two runs $\ln P=$ -7341.9 and -7342.6 ; three runs -7345.5 to -7345.7$)$ and the next highest $\log$ likelihood was for $K=2$ (ln $P=$ $-7464.7)$, which also had more variability in scores between runs. Panmixia is further supported by more traditional analyses of population subdivision. For example, the overall $F_{\mathrm{ST}}$ estimate from all populations was very low $\left(F_{\mathrm{ST}}=\right.$ $0.0019)$ and nonsignificant $(p>0.05)$. In addition, pairwise $F_{\mathrm{ST}}$ estimates among study sites ranged from -0.0009 to 0.0076. Only two pairwise comparisons (DV-LR and LV-SV) were marginally significant $(p<0.05)$. However, following a Bonferroni correction, these comparisons were insignificant. An AMOVA utilizing genotypes from each valley (i.e., DV-LV and JV-SV, see Methods) and the ridge yielded a similar trend, as over $99 \%$ of the variation was attributed to within population variation.

Overall, the observation of little genetic/geographic structuring is supported by assignment tests, which indicated that only 57 raccoons (31\%) were assigned to their population of capture or, in the case of road-killed animals, death location (Table 3). Tests revealed 68 misclassifications from valley populations to the ridge population (four pairwise comparisons), 41 were noted across the ridge (e.g., valley system to

TABle 3. Numbers of Individual Raccoons (PRocyon lotor) Assigned to Each Population (Study Site) in Southwestern Pennsylvania Using Bayesian-based Assignment Tests

\begin{tabular}{lccccc}
\hline & \multicolumn{5}{c}{ Locations $^{\mathrm{a}}$} \\
\cline { 2 - 6 } Locations & $L R$ & $L V$ & $J V$ & $D V$ & $S V$ \\
\hline LR & $12(31)^{\mathrm{a}}$ & $5,19^{\mathrm{c}}$ & 14,12 & 2,7 & 6,3 \\
LV & $24^{\mathrm{b}}$ & $10(21)$ & 16,4 & 1,5 & 2,1 \\
JV & 26 & 20 & $26(46)$ & 8,6 & 6,7 \\
DV & 9 & 6 & 14 & $4(18)$ & 0,4 \\
SV & 9 & 3 & 13 & 4 & $5(25)$ \\
\hline
\end{tabular}

LR, Laurel Ridge; LV, Ligonier Valley; JV, Jennerstown Valley; DV, Donegal Valley; SV, Somerset Valley.

aThe diagonal represents the number of individuals assigned to their population of capture (\% correctly assigned in parentheses).

bNumbers below the diagonal represent the number of individuals misclassified among population pairs.

'Numbers above the diagonal (separated by a comma) represent the number of individuals misclassified from each population for each population pair. These data are listed in the same order that the populations are presented.

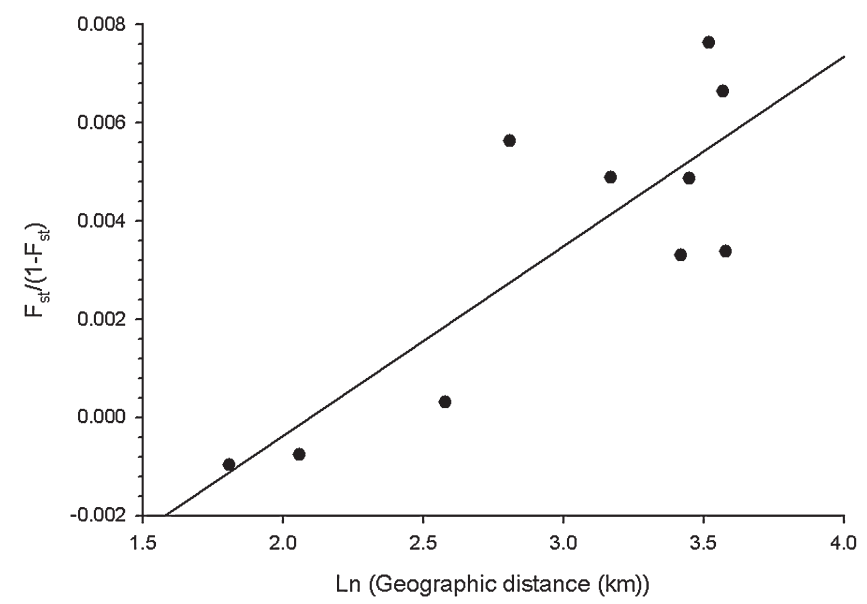

FIG. 2. Regression analysis of pairwise Slatkin's linearized $F_{\mathrm{ST}}$ values regressed on pairwise natural logarithm-transformed geographic distances between study sites of raccoons in southwestern Pennsylvania $\left(r^{2}=0.69\right.$, Mantel probability $<0.01,9,000$ permutations).

valley system; four pairwise comparisons), and 19 were noted within valley systems (e.g., misclassifications amongst LV-DV and JV-SV). Of interest, over twice as many misclassifications were noted among the JV-SV valley system (23.9 $\mathrm{km}$ ) when compared to the LV-DV system $(36.0 \mathrm{~km})$, which could imply an influence from geographic distance.

A significant positive relationship was observed between pairwise geographic distances and pairwise Slatkin's linearized $F_{\mathrm{ST}}$ values $\left(r^{2}=0.69\right.$, probability $<0.01,9,000$ permutations; Fig. 2). This analysis suggests that geographic distance appears to influence the weak genetic structuring of raccoon populations in this region. Notably, this association was observed at distances less than $37 \mathrm{~km}$.

\section{Discussion}

Overall, the raccoon populations we sampled were panmictic. As such, analyses suggest that neither ridges nor valleys influence raccoon gene flow meaningfully over the long term within the study area we sampled. Consequently, these data suggest that the ridge we studied is a poor natural "barrier" to complement ORV campaigns over the long-term. In addition, these data also indicate that although rabies virus is likely trafficked within valley systems, it is also likely that it is trafficked between valley systems.

Recent theoretical modeling efforts have indicated that large rivers may act as semipermeable barriers to rabies propagation (Smith et al. 2002). In addition, mountains have been suggested as potential physiographic barriers to rabies virus trafficking (Carey et al. 1978, Moore 1999). Elevation and habitat characteristics may be important facets associated with the incidence and distinctiveness of rabies epizootics (Childs et al. 2001). However, few attempts have been made to quantify these variables (Smith et al. 2002). Insofar as the analyses from our study indicate, the major geographic feature in this study area, Laurel Ridge, poses very little hindrance to raccoon gene flow. However, geographic distance appears to influence the weak genetic structuring observed over the geographic expanse of the study area. Additional 
sampling over a greater geographic area and/or more of this physiographic system will reveal if this a general trend or a local anomaly.

It has been suggested that a major corridor of rabies diffusion through Pennsylvania was through the ridge-and-valley portion of the state and that the Allegheny Mountain range may have acted as a restraint to the rapid westward spread of the raccoon rabies virus variant (Moore 1999). For obvious reasons, the natural "path of least resistance" for the virus within this geographic system would likely be through valleys via raccoon movement. This may have indeed been the case when rabies initially reached Pennsylvania, as trends in the spread of a strain of a rabies virus associated with gray fox have also been suggested to follow the orientation of valleys in Virginia (Carey et al. 1978). However, analyses from this study do not support quintessential valley corridors for the spread of the raccoon variant of rabies virus, as high gene flow rates were detected, in general, without regards to geography. It has been noted in a different virus-host association that the presence of physiographic barriers, such as ridges, may contribute to the enzootic maintenance and the directional spread of rabies virus by physically disrupting the continuity of habitat most suitable to gray foxes (Carey et al. 1978). Although formal density estimates were not conducted during this project, a simple "back of the envelope" calculation from capture per unit effort data would indicate that raccoon densities in the adjacent valleys are multifold higher than on Laurel Ridge. Nonetheless, raccoons were eventually captured on the ridge in reasonable numbers. Considering that this species is highly adaptable and occupies a variety of habitats such as riparian areas, mixed deciduous forests, and even semidesert shrublands in the west (Fitzgerald et al. 1994) and it eats a variety of foods of both plant and animal origin (e.g., an omnivorous opportunist; Fitzgerald et al. 1994, Schmidly 2004), finding habitats truly inhospitable for this mammal in the United States might be a difficult task, with the exception of true deserts and areas of extreme elevation. Overall, the diversity of habitats this mesopredator can exploit, as well as its sundry diet, suggest that this species could be considered a generalist in most situations. This implies that only geographic features with uninviting habitats, few resources, and/or major physical impediments (e.g., major rivers; Smith et al. 2002) to raccoon movement will likely provide key physiographic elements to enhance ORV in this area.

In general, this ridge and other areas of similar habitat and elevation do not appear to be adequate geographic features for natural "barriers" to enhance ORV of raccoons. This suggests that the typical large widths of raccoon ORV zones (e.g., $\geq 24 \mathrm{~km}$ ) are not only warranted but essential to ORV barrier success. This is apparent when one considers that analyses suggested that geographic distance appeared to influence the weak genetic structuring over the study area. Nonetheless, certain characteristics of ridges, such as spur valleys, may be useful for strategic ORV of this species (R.B. Puskas et al., unpublished data). In addition, the analyses reported herein are based on a population genetics perspective over a relatively small geographic area; as such, regional and movement studies might support a similar, but slightly different view. Notably, several long distance movements (e.g., $>100 \mathrm{~km}$ ) by raccoons have been reported, although this appears to be fairly uncommon and variable by region (see Lotze and Anderson 1979).
Within the United States, translocations of raccoons from one region to another have been carried out on occasion (Lotze and Anderson 1979). Risk estimates of long-distance raccoon translocation are crucial for forecast modeling the spread of rabies infection across geographic locations (Smith et al. 2002). Similarly, nuisance raccoon translocation on a more local scale not only could traffic rabies virus from one location to the next, but also could account for some of the perceived gene flow in this study. Nonetheless, the overall trend from these data is quite clear and is supported by multiple analyses. Although raccoon translocation could have occurred in our study area, the magnitude and consistency of our results suggest that it was unlikely to account for the level of gene flow we documented across this region.

The timely publication of multiple microsatellite primers (Cullingham et al. 2006), designed from raccoons, proved useful to better understand raccoon ecology and potential patterns of rabies transmission and trafficking at relatively small spatial scales. The large number of microsatellite loci now available for raccoons (see Cullingham et al. 2006, Fike et al. 2007, Siripunkaw et al. 2008) will allow for similar studies to be easily and inexpensively conducted in the future. These markers possess the utility to provide basic ecological information of raccoons and also provide key details about raccoon population structure that can be used to manipulate ORV activities in heterogeneous landscapes.

Of interest, similar associations of genetic structuring for other small carnivore species have been reported. For example, Broquet et al. (2006) found weak genetic structuring among populations of American marten (Martes Americana) in Canada and showed a pattern of isolation by distance in one of two landscapes. However, fishers (Martes pennanti) have yielded high levels of genetic structure in certain situations (Wisely et al. 2004).

In summary, this study suggests that the raccoons we studied in southwestern Pennsylvania form a large, panmictic population. None of the geographic features analyzed (e.g., ridges and valleys) yielded any significant evidence as a hindrance or a major corridor to raccoon movement and gene flow. However, a strong signature of isolation by distance was noted. Combined, these data suggest that the widths of ORV zones are crucial to forming a rabies virus barrier with ORV rather than relying on geographic features that, at least in this ecotype, appear to provide little assistance in acting as natural barriers over the long-term.

\section{Acknowledgments}

We are indebted to T. Roland (Pennsylvania Wildlife Services [PA WS]), A. Hess (PA WS), B. Zahuranic (PA WS), J. Duncan (PA WS), E. Swope (PA WS), and K. MacCarthy (National Wildlife Research Center [NWRC]) for field assistance, to several public/private land stewards for logistical assistance, to D. Slate (National Rabies Management Program [NRMP]) and R. Chipman (NRMP) for assistance with study design, and to R.G. McLean (NWRC) for providing assistance with study design and valuable comments on earlier versions of this manuscript.

\section{Disclosure Statement}

Funding for this work was provided by the United States Department of Agriculture. 


\section{References}

Blanchong, JA, Scribner, KT, Kravchenko, AN, Winterstein, SR. $\mathrm{Tb}$-infected deer are more closely related than non-infected deer. Biol Lett 2007; 3:103-105.

Broquet, T, Johnson, CA, Petit, E, Thompson, I, et al. Dispersal and genetic structure in the American marten, Martes Americana. Mol Ecol 2006; 15:1689-1697.

Carey, AB, Giles, RH, McLean, RG. The landscape epidemiology of rabies in Virginia. Am J Trop Med Hyg 1978; 27:573-580.

Childs, JE, Curns, AT, Dey, ME, Real, LA, et al. Predicting the local dynamics of epizootic rabies among raccoons in the United States. Proc Natl Acad Sci U S A 2000; 97:13666-13671.

Childs, JE, Curns, AT, Dey, ME, Real, LA, et al. Rabies epizootics among raccoons vary along a north-south gradient in the eastern United States. Vector-Borne Zoonotic Dis 2001; 1:253-267.

Cullingham, CI, Kyle, CJ, White, BN. Isolation, characterization and multiplex genotyping of raccoon tetranucleotide microsatellite loci. Mol Ecol Notes 2006; 6:1030-1032.

Excoffier, L, Laval, G, Schneider, S. Arlequin ver. 3.0: an integrated software package for population genetics data analysis. Evolutionary Bioinformatics 2005; 1:47-50.

Faircloth, BC. GMCONVERT: file conversion for GENEMAPPER output files. Mol Ecol Notes 2006; 6:968-970.

Fike, JA, Drauch, AM, Beasley, JC, Dharmarajan, G, et al. Development of 14 multiplexed microsatellite loci for raccoons Procyon lotor. Mol Ecol Notes 2007; 7:525-527.

Fitzgerald, JP, Meaney, CA, Armstrong, DM. Mammals of Colorado. Niwot: University Press of Colorado; 1994.

Glaubitz, JC. CONVERT: A user-friendly program to reformat diploid genotypic data for commonly used population genetic software packages. Mol Ecol Notes 2004; 4:309-310.

Hampton, JO, Spencer, PBS, Alpers, DL, Twigg, LE, et al. Molecular techniques, wildlife management and the importance of genetic population structure and dispersal: a case study with feral pigs. J Appl Ecol 2004; 41:735-743.

Lotze, J-H, Anderson, S. Procyon lotor. Mammalian Species 1979; 119:1-8.

Manel, S, Schwartz, MK, Luikart, G, Taberlet, P. Landscape genetics: combining landscape ecology and population genetics. Trends Ecol Evol 2003; 18:189-197.

McLean, RG. Raccoon rabies. In Baer, GM, ed. The Natural History of Rabies, Volume II. New York: Academic Press, Inc.; 1975:53-77.

Moore, DA. Spatial diffusion of raccoon rabies in Pennsylvania, USA. Prev Vet Med 1999; 40:19-32.

Piry, S, Alapetite, A, Cornuet, J-M, Paetkau, D, et al. GENECLASS2: a software for genetic assignment and firstgeneration migrant detection. J Hered 2004; 95:536-539.
Pritchard, JK, Stephens, M, Donnelly, P. Inference of population structure using multilocus genotype data. Genetics 2000; 155:945-959.

Rannala, B, Mountain, JL. Detecting immigration by using multilocus genotypes. Proc Natl Acad Sci U S A 1997; 94:9197-9201.

Rice, WR. Analyzing tables of statistical tests. Evolution 1989; 43:223-225.

Root, JJ, Black, WC, Calisher, CH, Wilson, KR, et al. Analyses of gene flow among populations of deer mice (Peromyscus maniculatus) at sites near hantavirus pulmonary syndrome casepatient residences. J Wildl Dis 2003; 39:287-298.

Root, JJ, Black, WC, Calisher CH, Wilson KR, et al. Genetic relatedness of deer mice (Peromyscus maniculatus) infected with Sin Nombre virus. Vector-Borne Zoonotic Dis 2004; 4:149-157.

Schmidly, DJ. The Mammals of Texas, revised edition. Austin: University of Texas Press; 2004.

Siripunkaw, C, Kongrit, C, Faries, KM, Monello, RJ, et al. Isolation and characterization of polymorphic microsatellite loci in the raccoon (Procyon lotor). Molecular Ecology Resources 2008; 8:199-201.

Slatkin, M. A measure of population subdivision based on microsatellite allele frequencies. Genetics 1995; 139:457-462.

Smith, DL, Lucey, B, Waller, LA, Childs, JE, et al. Predicting the spatial dynamics of rabies epidemics on heterogeneous landscapes. Proc Natl Acad Sci U S A 2002; 99:3668-3672.

USDA. Cooperative Rabies Management Program National Report 2004. USDA-AHPIS-Wildlife Services, Concord, New Hampshire, 2004.

USDA. Wildlife Services-Pennsylvania. State Report, 2006. www.aphis.usda.gov. Accessed online January 2006.

Weir, BS, Cockerham, CC. Estimating F-statistics for the analysis of population structure. Evolution 1984; 38:1358-1370.

Winkler, WG, Jenkins, SR. Raccoon rabies. In Bear, GM, ed. The Natural History of Rabies, 2nd ed. Boca Raton, Florida: CRC Press; 1991:325-340.

Wisely, SM, Buskirk, SW, Russell, GA, Aubry, KB, et al. Genetic diversity and structure of the fisher (Martes pennanti) in a peninsular and peripheral metapopulation. J Mammal 2004; 85:640-648

Address correspondence to: Dr. Jeff Root USDA/APHIS/WS

National Wildlife Research Center 4101 LaPorte Avenue Fort Collins, CO 80521

E-mail: jeff.root@aphis.usda.gov 